\title{
Comparison of three diagnostic methods in the diagnosis of cryptosporidiosis and gp60 subtyping of Cryptosporidium parvum in diarrheic calves in Central Anatolia Region of Turkey
}

\author{
Alparslan Yildirim ${ }^{1}$, Ferda Sevinc ${ }^{2}$, Zuhal Onder ${ }^{{ }^{*}}$, Onder Duzlu ${ }^{1}$, Ozlem Derinbay Ekici ${ }^{2}$, Nermin Isik ${ }^{2}$, \\ Arif Ciloglu ${ }^{1}$ Emrah Simsek ${ }^{3}$, Gamze Yetismis ${ }^{1}$, Abdullah Inci $^{1}$
}

\begin{abstract}
The aim of this study was to compare three diagnostic methods for the diagnosis of cryptosporidiosis and to detect subtypes of Cryptosporidium parvum by sequences analyses of gp60 gene in diarrheic calves in several herds in Konya province located in Central Anatolia Region of Turkey. Fecal samples were collected from a total of 194 pre-weaned calves ( $\mathrm{n}=158, \leq 15$ days old, and $n=36,15$ to 40 days old), with diarrhoea. For comparative diagnosis, all samples were examined by modified Ziehl-Neelsen staining of fecal smears for the presence of oocyst, nested PCR-RFLP of SSU rRNA and TaqMan qPCR for the detection of Cryptosporidium DNA. A total of 92 (47.4\%) and 104 (53.6\%) out of the examined samples were found positive by microscopic examination and molecular tools, respectively. The diagnostic sensitivity and specificity of microscopic identification were determined as $88.5 \%$ and $100.0 \%$, respectively compared to molecular assays. Cryptosporidium parvum was the only detected species in all positive samples by species-specific qPCR and nested PCR-RFLP assays. Species identifications were further confirmed by sequence analyses of the SSU rRNA PCR products. There was no statistically significant difference in $C$. parvum prevalence between early pre-weaned calves and calves older than 15 days. The sequence analyses of the gp 60 gene of C. parvum isolates revealed a one subtype IIaA13G2R1 belonging to zoonotic family IIa in diarrheic calves
\end{abstract}

Keywords: Cryptosporidium parvum, diarrheic calves, gp60 subtype, nested PCR-RFLP, prevalence, TaqMan qPCR, Turkey

${ }^{1}$ Erciyes University, Faculty of Veterinary Medicine, Parasitology Department, Kayseri, Turkey

${ }^{2}$ Selcuk University, Faculty of Veterinary Medicine, Parasitology Department, Konya, Turkey

${ }^{3}$ Erciyes University, Faculty of Veterinary Medicine, Department of Preclinical Science, Kayseri, Turkey

Corresponding author: Assist. Prof. Dr. Zuhal ONDER, Parasitology Department, Faculty of Veterinary Medicine, Erciyes University, Kayseri 38090, Turkey. Phone: +90-352-339 2312, Fax: +90352-339 2312, E-mail: zuhalbiskin@erciyes.edu.tr

DOI: 10.2478/ebtj-2021-0010

(C) 2021 Authors. This work was licensed under the Creative Commons Attribution-NonCommercialNoDerivs 4.0 License.

\section{Introduction}

Cryptosporidium species, the causative agents of cryptosporidiosis, are the important opportunistic intestinal pathogens that can infect various hosts including cattle and humans (1-3). The ingestion of contaminated water and foods is the main risk factor for calves and other hosts as well as humans for Cryptosporidium spp. infections $(4,5)$. Cattle, especially pre-weaned calves are known as the most common hosts of Cryptosporidium spp. with high infection and oocyst excretion rates in their feces (6,7). Cryptosporidium parvum is recognized as the primary zoonotic species causing cryptosporidiosis in pre-weaned calves resulting in diarrhoea, weight loss, dehydration, delayed growth, and important economic losses related to calf morbidity and mortality $(6,8)$. Furthermore, young calves are regarded as an important potential source of human cryptosporidiosis in various outbreaks worldwide (9).

Several techniques are used for the laboratory detection of Cryptosporidium in fecal samples. The oocysts of Cryptosporidium cannot concentrate well using standard concentration techniques but can be identified by microscopy combined with various staining methods, i.e. modified Ziehl-Neelsen of fecal smears (10). On the other hand, the diagnostic efficiency of conventional microscopic examination might be low due to sporadic oocyst shedding and the presence of few oocysts in the fecal samples. Examination of the stained fecal smears also has a disadvantage for the detection of Cryptosporidium because the oocysts can easily be confused with other materials (e.g fecal debris, yeast 
cells, and bacterial spores) present in the smears (11). In spite of higher costs and needs for infrastructure needs and high technical expertise, the use of molecular tools for the detection of Cryptosporidium has the advantages of improved sensitivity and specificity. These methods also allowed us to better understand the genetic diversity of Cryptosporidium species that are highly host-specific in genotype and subtype levels, transmission routes, and related impacts on public health $(8,12)$. Currently, small-subunit rRNA (SSU rRNA) gene-based nested PCR-RFLP analysis have been developed for the detection and identification of Cryptosporidium species in fecal and environmental samples (13-15). A quantitative real-time PCR (qPCR) assay has also been developed to identify and quantify Cryptosporidium DNA in fecal and various environmental samples (16-18).

Host-specific and zoonotic subtypes have been described using sequence analysis of the $60 \mathrm{kDa}$ glycoprotein (gp60) gene that is widely used in subtyping of $C$. parvum because of its high polymorphism $(19,20)$. To date, at least 20 subtype families have been described within C. parvum (21). Subtypes IIa and IId are considered zoonotic subtypes found in both humans and ruminants. The subtype family IIa of $C$. parvum is common in calves and the IIaA15G2R1 is the most prevalent subtype in many countries $(9,21,22)$.

Cryptosporidium parvum is known as one of the main causative agents of neonatal calf diarrhoea in herds in Turkey. However, there have been little data on the molecular characterization and subtyping of $C$. parvum in pre-weaned calves in Turkey (23-25). This study was conducted to evaluate diagnostic efficiency and usefulness of the nested PCR, Real-Time PCR assay and conventional modified Ziehl-Neelsen staining of the faecal smears comparatively, for the detection of cryptosporidiosis in calves with neonatal diarrhoea in the traditional farms of private smallholders in three districts of Konya province located in Central Anatolia Region of Turkey. Cryptosporidium parvum subtypes were also investigated by sequence analysis of the gp60 gene to reveal zoonotic transmission dynamics of cryptosporidiosis in the research area.

\section{Materials and Methods \\ Sampling strategy, data collection and identification of oocysts}

Farms from three districts (Merkez, Karatay, and Selcuklu) were selected between 2011 and 2012 according to local veterinarians' opinion. The inclusion criterion for farms was a size of 5 to 50 calves traditionally owned by private smallholders with a history of neonatal calf diarrhoea. Based on sample size calculations (EPIDAT 3.1), a total of 20 farms were selected from a total of 208 officially recorded farms belonged to private smallholders in the research area. Environmental conditions of the farms included in the study shared common characteristics such as similar climatic conditions, traditional barns and pasture based raising of calves. A total of 194 fecal samples from early pre-weaned ( $\mathrm{n}=158, \leq 15$ days old) and pre-weaned calves ( $n=36,15$ to 40 days old) with neonatal calf diarrhoea were collected from the predefined farms ( 5 to 15 calves per farm). Approximately 30-50 g fecal samples were taken from fresh droppings on the ground after defecation, then immediately placed into a sterile plastic container and held at $4^{\circ} \mathrm{C}$ until analysis. The fecal smears were prepared and stained using the modified Ziehl-Neelsen staining method for the presence of oocysts (26).

\section{Genomic DNA extraction}

$200 \mathrm{mg}$ of each fecal sample within a microcentrifuge tube were frozen in liquid nitrogen and subsequently heated before DNA extraction. Genomic DNA (gDNA) was extracted from disrupted samples by the QIAamp DNA Stool Mini kit (Qiagen, Hilden, Germany) according to the manufacturer's instructions. DNA concentrations of the extracts were measured with the Qubit Fluorometric Quantitation (Thermo Fisher Scientific, USA) to optimizing the amount used in the PCR master mix. The extracted DNAs were then preserved at $-20^{\circ} \mathrm{C}$ until the time of molecular analysis.

\section{Quantitative Real time PCR (qPCR)}

TaqMan qPCR assay with primers and probes targeting Cryptosporidium at genus level and C. parvum was carried out according to Jothikumar et al. (27). A CFX Connect Real-Time PCR Detection System (Bio-Rad, Hercules, CA, USA) was used for all qPCR analysis. The reaction conditions for the qPCR were adjusted according to the protocol described by Jothikumar et al. (27) using SsoAdvanced Universal Probes Supermix (Bio-Rad, Hercules, CA, USA) and 10-30 ng template DNA in each reaction

\section{Nested PCR-RFLP of SSU rRNA and amplification of $g p 60$}

gDNA isolates were analyzed with nested PCR to amplify approximately $840 \mathrm{bp}$ and $850 \mathrm{bp}$ fragments of the SSU rRNA and gp60 gene regions, respectively with specific primers following the protocols previously described (28-30). PCR products were electrophoretically resolved in $1.5 \%$ agarose gels containing SYBR ${ }^{\mathrm{mix}}$ Safe stain (Thermo Fisher Scientific, USA) and visualized using Fusion FX Gel Documentation System (Vilber Lourmat, France). For RFLP analysis, secondary PCR products of the SSU rRNA gene were digested using FastDigest SspI and FastDigest MboII (Thermo Fisher Scientific, USA). Identification of Cryptosporidium species was performed according to restriction patterns described previously (31).

\section{Sequence analysis of SSU rRNA and gp60 subtyping}

All gel-purified secondary PCR products of the two target genes (SSU rRNA and gp60) were sequenced (Macrogen, Netherlands) in both directions to confirm RFLP results and detect subtypes of $C$. parvum. The nucleotide sequences were assembled with Geneious Prime 11.0.2 software (http://www.geneious.com). The consensus sequences were aligned with reference sequences downloaded from GenBank by MUSCLE (32) using Geneious prime. Subtypes of $C$. parvum were named 
with established for Cryptosporidium spp. gp60 nomenclature system (33).

\section{Results}

\section{Identification and distribution of $C$. parvum accord- ing to the diagnostic methods}

A total of 92 and 104 samples were found positive by utilizing microscopic examination (Figure 1a) and molecular assays, respectively (Table 1) and there was full agreement between the results of these two tests. Microscopic analysis revealed a lower number of Cryptosporidium positivity and its diagnostic sensitivity and specificity were determined as $88.5 \%$ and $100.0 \%$ compared to molecular tools, respectively (Table 1). 15 of samples from diarrheic pre-weaned calves were found positive in the C. parvum species-specific real-time PCR assay (Figure 1c) and there was no positivity at the genus level without C. parvum. vealed three $(449,267$, and $108 \mathrm{bp}$ ) and two (771 and $76 \mathrm{bp}$ ) band profiles specific to $C$. parvum with the restriction enzymes SspI and MboII, respectively (Figure 1b) confirming the qPCR results. No mixed infections were found in the examined specimens with the RFLP analysis of the SSU rRNA gene. DNA sequence analysis and BLAST search of the SSU rRNA nucleotide sequences of the isolates showed species-based homology with the corresponding sequences of $C$. parvum in GenBank further confirming the results of qPCR and RFLP analysis. SSU rRNA sequences of $C$. parvum characterized in the study were deposited to the NCBI GenBank database under accession numbers KF008173-75.

\section{C. parvum subtypes with gp60 sequencing}

Gp60 gene was successfully amplified and sequenced from isolates of all $C$. parvum positive samples. Sequence analysis identified only one subtype belonging to family IIa (Table 2).

Table 1. Comparison of the results of microscopic examination and molecular assays in the detection of Cryptosporidium in calves and evaluation of diagnostic sensitivity and specificity.

\begin{tabular}{|c|c|c|c|c|c|}
\hline \multirow{2}{*}{\multicolumn{2}{|c|}{ Method }} & \multicolumn{2}{|c|}{ Molecular tools } & \multirow{2}{*}{ Sensitivity } & \multirow{2}{*}{ Specificity } \\
\hline & & Positive & Negative & & \\
\hline \multirow{2}{*}{ Microscopy } & Positive & 92 & 0 & $85.5 \%$ & $100 \%$ \\
\hline & Negative & 12 & 90 & $(80.7-93.9 \%)$ & $(96.0-100.0 \%)$ \\
\hline \multicolumn{2}{|c|}{ Total } & 104 & 90 & & \\
\hline
\end{tabular}

The distribution of $C$. parvum over the age groups of preweaned calves with diarrhoea based on the molecular assays is presented in Table 2 . The prevalence in early pre-weaned calves ( $\leq 15$ days old) $(56.3 \%)$ was higher than the prevalence in preweaned calves ( 15 to 40 days old) (41.7\%). However, this difference was not statistically significant $(\mathrm{p}>0.05)$ (Table 2$)$.
IIaA13G2R1 subtype has 13 copies of TCA (A) and, 2 copies of TCG $(\mathrm{G})$ trinucleotide repeat encoding serine, and one copy of the sequence ACATCA (R1) following the trinucleotide repeat. Gp60 sequences of the isolates were submitted to the NCBI GenBank database under accession numbers KF008176-85.

Table 2. Distribution and subtype of $C$. parvum over age groups of the examined calves based on molecular diagnostic tests used in the study.

\begin{tabular}{|c|c|c|c|c|c|}
\hline \multirow{2}{*}{$\begin{array}{l}\text { Age group } \\
\text { (days) }\end{array}$} & \multirow{2}{*}{ Total no. of samples } & \multicolumn{4}{|c|}{ Cryptosporidium parvum } \\
\hline & & No. positive (\%) & $x^{2}$ & $\mathrm{p}$ & gp60 subtype \\
\hline $\begin{array}{l}\text { Early pre-weaned calves } \\
\qquad(\leq 15)\end{array}$ & 158 & $89(56.3)$ & 2.535 & 0.139 & IIaA13G2R1 \\
\hline $\begin{array}{c}\text { Pre-weaned calves } \\
(15-40)\end{array}$ & 36 & $15(41.7)$ & & & \\
\hline Total & 194 & $104(53.6)$ & & & \\
\hline
\end{tabular}

\section{RFLP and sequence analysis of SSU rRNA}

RFLP analysis of all SSU rRNA nested PCR products from the isolates that were identified as C. parvum in TaqMan qPCR re-

\section{Discussion}

Cryptosporidium parvum is an important causative pathogen of neonatal calf diarrhoea and definitive and differentiative diagnosis is crucial for effective treatment and taking control 


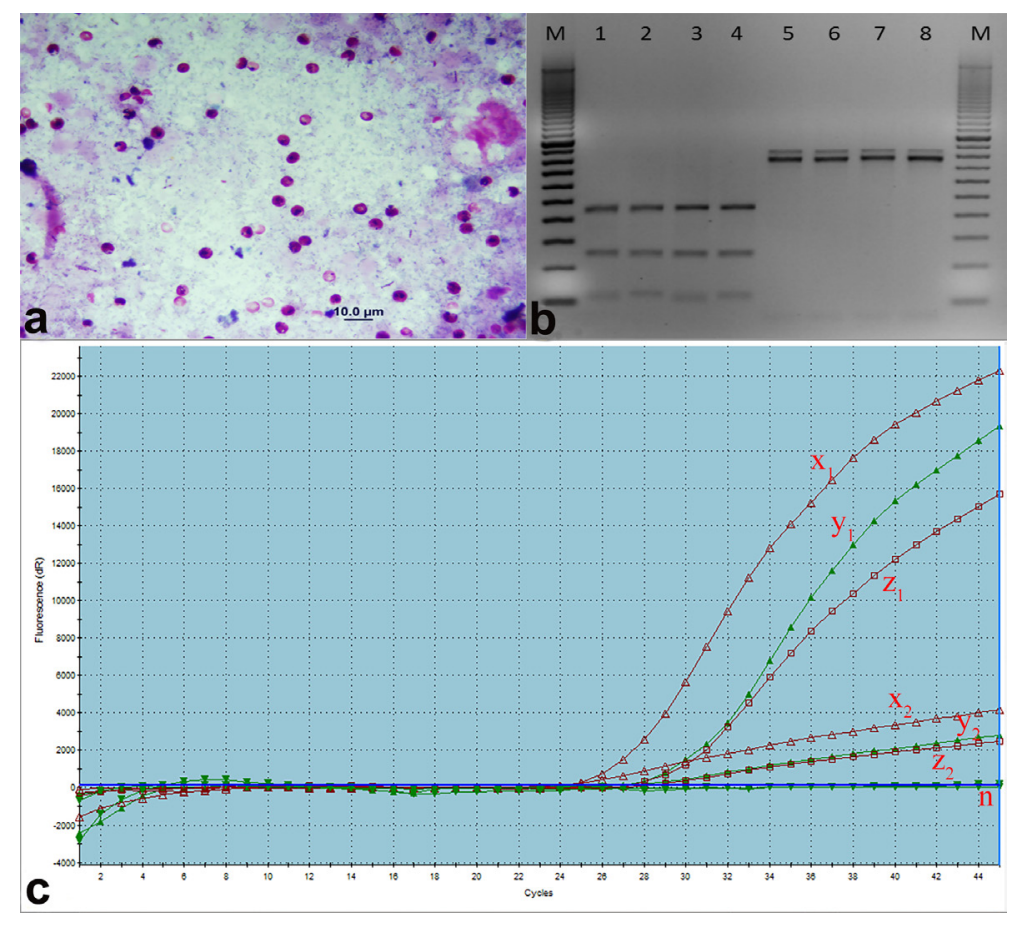

Figure 1. a: Cryptosporidium oocysts in fecal smears stained with the Ziehl-Neelsen by microscopic examination $(\times 1000)$; b: Electrophoretic profiles of the SSU rRNA PCR products of C. parvum isolates digested with the endonucleases $S s p I$ (lanes 1 to 4 ) and MboII (lanes 5 to 8). M: Molecular size marker (100bp); c: Amplification curves with TaqMan real-time PCR analyses. x1, y1 and z1: C. parvum species specific qPCR curves; $\mathrm{x} 2$, y2 and z2: Cryptosporidium genus specific qPCR curves belonging to the same isolates; n: No DNA control and negative samples

measurements against the disease (9). Therefore, the diagnosis of cryptosporidiosis needs to be highly specific and sensitive. Even though microscopy is currently the common and practicable method in the diagnosis of cryptosporidiosis it has the disadvantages of poor sensitivity and specificity, especially in the case of sporadic shedding of oocyst and also low oocysts in fecal samples. Besides, the oocysts can easily be confused with other particles present in the smears, especially in the absence of considerable training and expertise. Furthermore, it is difficult to distinguish Cryptosporidium species (34). In our study lower positivity of Cryptosporidium was detected using conventional microscopic examination of the fecal smears compared with molecular assays resulting in a decreased sensitivity of $88.5 \%$. However, the specificity was determined as $100.0 \%$. This result is by the previous studies that used various molecular techniques to detect Cryptosporidium species in human and animal fecal and environmental samples (9,35). Nested PCR-RFLP and qPCR assays determined the same samples as positive for Cryptosporidium revealing the high sensitivity and specificity of both techniques in our study. Despite their high accuracy in the diagnoses, these molecular assays have the disadvantage of being time-consuming and having many steps in the diagnostic procedure. Furthermore, they are also expensive due to the complex equipment needed to run assays.

SSU rRNA-based PCR is the most commonly used assay in many epidemiological studies to detect and identify Cryptosporidium species. However, this technique requires further analysis involving RFLP or DNA sequencing to distinguish species $(14,29,31,36,37)$. Recently, a quantitative real-time PCR assay has been developed for the identification of Cryptosporidium species and $C$. parvum strains in clinical samples and water matrices $(14,16)$. qPCR has several advantages including the elimination of post-amplification handling, easier automation, reducing contamination risk and assay times, and processing of high numbers of samples $(27,38,39)$. Jothikumar et al. (27) reported that the duplex TaqMan qPCR approach can specifically detect all Cryptosporidium species at the genus level and C. parvum in a single reaction. Our results agree with the findings of Jothikumar et al. (27) and also sequence analysis of the SSU rRNA gene region confirmed the results of the qPCR assay. Development of accurate qPCR assays to determine and discriminate the bovine Cryptosporidium species might be useful for epidemiological investigations.

We determined high $C$. parvum infection in pre-weaned calves with diarrhoea with an overall prevalence of 53.6\%. Neonatal calf diarrhoea has a multifactorial etiology and C. parvum is recognized as frequently associated with neonatal diarrhoea $(8,40)$. The dominancy of $C$. parvum as the causative pathogen of diarrhoea in pre-waned calves has been also reported in the herds of several countries $(29,41-43)$ as well as Turkey $(24,25,44)$. On the other hand, the other bovine Cryptosporidium species such as $C$. bovis and $C$. ryanae are responsible for the majority of cryptosporidiosis in post-weaned calves and heifers (25,45-49). The other bovine Cryptosporidium species, 
C. andersoni is commonly found in adult cattle $(9,45,50)$. The absence of all the above species in diarrheic calves in our study further confirmed the age-related future of the bovine Cryptosporidium species. The predominance of $C$. parvum in our study is somewhat expected and consistent with the age of the studied calves, as this is the most frequent species in neonate animals. This approach allowed us to identify a unique subtype IIaA13G2R1 of C. parvum, within the family IIa, which is widely recognized for its zoonotic potential. This subtype has been previously characterized as a common subtype in calves. On the other hand, some researchers also reported the presence of $C$. bovis and C. ryanae in pre-weaned calves in the absence of C. parvum (49,51). Conversely, C. bovis was determined to be the most prevalent species in pre-weaned dairy calves in some countries such as China (52,53), Sweden (54), Ethiopia (49) and Western Australia and New South Wales (55), and some authors highlighted that this status may be associated with different farming practices and seasonal differences (56). We also determined that $C$. parvum was more prevalent in the early pre-weaned calves ( $\leq 15$ days old) than the pre-weaned calves of 15 to 40 days old. However, this difference was not statistically significant and $C$. parvum could affect pre-weaned calves during the growing period as indicated by several researchers (50,57-59).

Sequence analysis of the gp60 gene revealed the presence and wideness of unique subtype IIaA13G2R1 of $C$. parvum in the zoonotic IIa family in the study area. In addition to C. parvum speciation, we decided to pursue subtyping using a nested PCR assay targeting the gp60 gene followed by sequencing. IIaA13G2R1 has been previously characterized as a common subtype in calves from the different regions of Central Anatolia and Mediterranean regions in Turkey (25). This subtype has also been reported in calves in Canada (60), Belgium (61), Algeria (62), the Netherlands (63), in people with HIV/AIDS in Malaysia (64), in goat kids and lambs in Algeria (65), in ponies in the United States (66). The occurrence and wideness of IIaA13G2R1 in several ruminants, equids, and also humans indicate the risk of zoonotic transmission of cryptosporidiosis in the research area.

\section{Conclusion}

In conclusion, our study confirms the usefulness of nested PCR-RFLP and qPCR assays in the accurate diagnosis of Cryptosporidium in calves. Regarding the high prevalence of zoonotic subtype IIaA13G2R1, our results highlight the potential risk of pre-weaned calves for human infections with C. parvum in the research area. Thus, control measures should be considered for reducing the risk of the zoonotic transmission of $C$. parvum. Comparative molecular surveys on humans from different geographic regions, especially in farmworkers that are in close contact with $C$. parvum-infected animals are needed to improve our understanding of cryptosporidiosis epidemiology and C. parvum subtype diversity in Turkey.

\section{Acknowledgments}

This study was financially supported by Erciyes University Scientific and Technological Research Fund with the research project TSA-11-3748.

\section{Conflict of interest}

On behalf of all authors, the corresponding author states that there is no conflict of interest.

\section{References}

1. Ryan U. Cryptosporidium in birds, fish and amphibians. Exp Parasitol 2010;124:113-20.

2. Deng L, Chai Y, Luo R, Yang L, Yao J, Zhong Z, et al. Occurrence and genetic characteristics of Cryptosporidium spp. and Enterocytozoon bieneusi in pet red squirrels (Sciurus vulgaris) in China. Scientific Reports. Nature Publishing Group 2020;10:1-10.

3. Shirozu T, Soga A, Morishita Y, Seki N, Ko-ketsu M, Fukumoto S. Prevalence and phylogenetic analysis of Cryptosporidium infections in Yezo sika deer (Cervus nippon yesoensis) in the Tokachi sub-prefecture of Hokkaido, Japan. Parasitol Int. 2020;76:102064.

4. Baldursson S, Karanis P. Waterborne transmission of protozoan parasites: Review of worldwide outbreaks - An update 2004-2010. Water Res. 2011;45:6603-14.

5. Alsmark C, Nolskog P, Angervall AL, Toepfer M, Winiecka-Krusnell J, Bouwmeester J, et al. Two outbreaks of cryptosporidiosis associated with cattle spring pasture events. Vet Parasitol Reg Stud Reports 2018;14:71-4.

6. Thomson S, Hamilton CA, Hope JC, Katzer F, Mabbott NA, Morrison LJ, et al. Bovine cryptosporidiosis: impact, host-parasite interaction and control strategies. Vet Res. 2017;48:42.

7. Mammeri M, Chevillot A, Chenafi I, Thomas M, Julien C, Vallée I, et al. Molecular characterization of Cryptosporidium isolates from diarrheal dairy calves in France. Vet Parasitol Reg Stud Reports 2019;18:100323.

8. Lombardelli JA, Tomazic ML, Schnittger L, Tiranti KI. Prevalence of Cryptosporidium parvum in dairy calves and GP60 subtyping of diarrheic calves in central Argentina. Parasitol Res 2019;118:2079-86.

9. Xiao L. Molecular epidemiology of cryptosporidiosis: An update. Exp Parasitol 2010;124:80-9.

10. Casemore DP. ACP Broadsheet 128: June 1991. Laboratory methods for diagnosing cryptosporidiosis. J Clin Pathol 1991;44:445-51.

11. Connelly JT, Nugen SR, Borejsza-Wysocki W, Durst RA, Montagna RA, Baeumner AJ. Human pathogenic Cryptosporidium species bioanalytical detection method with single oocyst detection capability. Anal Bioanal Chem 2008;391:487-95.

12. Thompson RCA, Ash A. Molecular epidemiology of Giardia and Cryptosporidium infections. Infect Genet Evol 2016;40:315-23.

13. Xiao L, Alderisio K, Limor J, Royer M, Lal AA. Identification of species and sources of Cryptosporidium oo- 
cysts in storm waters with a small-subunit rRNA-based diagnostic and genotyping tool. Appl Environ Microbiol 2000;66:5492-8.

14. Manouchehri Naeini K, Asadi M, Hashemzade Chaleshtori M. Detection and Molecular Characterization of Cryptosporidium species in Recreational Waters of Chaharmahal va Bakhtiyari Province of Iran using nested-PCR-RFLP. Iran J Parasitol 2011;6:20-7.

15. Shahbazi P, Aligolzadeh A, Khordadmehr M, Hashemzadeh Farhang H, Katiraee F. Molecular study and genotyping of Cryptosporidium baileyi and Cryptosporidium parvum from free-range and commercial broiler chickens in Guilan province, Iran. Comp Immunol Microbiol Infect Dis 2020;69:101411.

16. Staggs SE, Beckman EM, Keely SP, Mackwan R, Ware MW, Moyer AP, et al. The applicability of TaqMan-Based quantitative Real-Time PCR assays for detecting and enumerating Cryptosporidium spp. oocysts in the environment. PLoS ONE 2013;8:e66562.

17. Burnet JB, Ogorzaly L, Tissier A, Penny C, Cauchie HM. Novel quantitative TaqMan real-time PCR assays for detection of Cryptosporidium at the genus level and genotyping of major human and cattle-infecting species. J App Microbiol 2013;114:1211-22.

18. Bouzid M, Elwin K, Nader JL, Chalmers RM, Hunter PR, Tyler KM. Novel real-time PCR assays for the specific detection of human infective Cryptosporidium species. Virulence. Taylor \& Francis 2016;7:395-9.

19. Rahmouni I, Essid R, Aoun K, Bouratbine A. Glycoprotein 60 diversity in Cryptosporidium parvum causing human and cattle cryptosporidiosis in the rural region of Northern Tunisia. Am J Trop Med Hyg 2014;90:346-50.

20. Ramo A, Monteagudo LV, Del Cacho E, Sánchez-Acedo C, Quílez J. Intra-Species genetic diversity and clonal structure of Cryptosporidium parvum in sheep farms in a confined geographical area in Northeastern Spain. PLoS ONE 2016;11:e0155336.

21. Feng Y, Ryan UM, Xiao L. Genetic diversity and population structure of Cryptosporidium. Trends Parasitol 2018;34:997-1011.

22. Aita J, Ichikawa-Seki M, Kinami A, Yaita S, Kumagai Y, Nishikawa Y, et al. Molecular characterization of Cryptosporidium parvum detected in Japanese black and Holstein calves in Iwate Prefecture and Tanegashima Island, Kagoshima Prefecture, Japan. J Vet Med Sci 2015;77:997-9.

23. Arslan MO, Ekinci AI. Determination of Cryptosporidium parvum subtypes in cattle in Kars province of Turkey. Kafkas Üniversitesi Veteriner Fakültesi Dergisi 2012;18.

24. Taylan-Ozkan A, Yasa-Duru S, Usluca S, Lysen C, Ye J, Roellig DM, et al. Cryptosporidium species and Cryptosporidium parvum subtypes in dairy calves and goat kids reared under traditional farming systems in Turkey. Exp Parasitol 2016;170:16-20.

25. Yildirim A, Adanir R, Inci A, Yukari BA, Duzlu O, Onder $\mathrm{Z}$, et al. Prevalence and genotyping of bovine Cryptospo- ridium species in the Mediterranean and Central Anatolia Region of Turkey. Comp Immunol Microbiol Infect Dis 2020;69:101425.

26. Casemore DP, Armstrong M, Sands RL. Laboratory diagnosis of cryptosporidiosis. J Clin Pathol 1985;38:1337-41.

27. Jothikumar N, da Silva AJ, Moura I, Qvarnstrom Y, Hill VR. Detection and differentiation of Cryptosporidium hominis and Cryptosporidium parvum by dual TaqMan assays. J Med Microbiol 2008;57:1099-105.

28. Xiao L, Morgan UM, Limor J, Escalante A, Arrowood M, Shulaw W, et al. Genetic diversity within Cryptosporidium parvum and related Cryptosporidium species. Appl Environ Microbiol 1999;65:3386-91.

29. Alves M, Xiao L, Sulaiman I, Lal AA, Matos O, Antunes F. Subgenotype analysis of Cryptosporidium isolates from humans, cattle, and zoo ruminants in Portugal. J Clin Microbiol 2003;41:2744-7.

30. Peng MM, Matos O, Gatei W, Das P, Stantic-Pavlinic M, Bern C, et al. A comparison of Cryptosporidium subgenotypes from several geographic regions. J Eukaryot Microbiol 2001;Suppl:28S-31S.

31. Feng Y, Ortega Y, He G, Das P, Xu M, Zhang X, et al. Wide geographic distribution of Cryptosporidium bovis and the deer-like genotype in bovines. Vet Parasitol 2007;144:1-9.

32. Edgar RC. MUSCLE: a multiple sequence alignment method with reduced time and space complexity. BMC Bioinformatics 2004;5:113.

33. Xiao L, Feng Y. Molecular epidemiologic tools for waterborne pathogens Cryptosporidium spp. and Giardia duodenalis. Food Waterborne Parasitol 2017;8-9:14-32.

34. Ahmed SA, Karanis P. Comparison of current methods used to detect Cryptosporidium oocysts in stools. Int J Hyg Environ Health 2018;221:743-63.

35. Chalmers RM, Katzer F. Looking for Cryptosporidium: the application of advances in detection and diagnosis. Trends Parasitol 2013;29:237-51.

36. Xiao L, Bern C, Limor J, Sulaiman I, Roberts J, Checkley W, et al. Identification of 5 types of Cryptosporidium parasites in children in Lima, Peru. J Infect Dis 2001;183:492-7.

37. McLauchlin J, Amar C, Pedraza-Díaz S, Nichols GL. Molecular epidemiological analysis of Cryptosporidium spp. in the United Kingdom: results of genotyping Cryptosporidium spp. in 1,705 fecal samples from humans and 105 fecal samples from livestock animals. J Clin Microbiol 2000;38:3984-90.

38. Bleve G, Rizzotti L, Dellaglio F, Torriani S. Development of reverse transcription (RT)-PCR and real-time RT-PCR assays for rapid detection and quantification of viable yeasts and molds contaminating yogurts and pasteurized food products. Appl Environ Microbiol 2003;69:4116-22.

39. Hadfield SJ, Robinson G, Elwin K, Chalmers RM. Detection and differentiation of Cryptosporidium spp. in human clinical samples by use of real-time PCR. J Clin Microbiol 2011;49:918-24.

40. Meganck V, Hoflack G, Piepers S, Opsomer G. Evaluation 
of a protocol to reduce the incidence of neonatal calf diarrhoea on dairy herds. Prev Vet Med 2015;118:64-70.

41. Soba B, Logar J. Genetic classification of Cryptosporidium isolates from humans and calves in Slovenia. Parasitology 2008;135:1263-70.

42. Quilez J, Torres E, Chalmers RM, Robinson G, Del Cacho E, Sanchez-Acedo C. Cryptosporidium species and subtype analysis from dairy calves in Spain. Parasitology 2008;135:1613-20.

43. Kaupke A, Rzeżutka A. Emergence of novel subtypes of Cryptosporidium parvum in calves in Poland. Parasitol Res 2015;114:4709-16.

44. Sevinc F, Irmak K, Sevinc M. The prevalence of Cryptosporidium parvum infection in the diarrhoiec and nondiarrhoeic calves. Revue Méd Vét 2003;5.

45. Fayer R, Santin M, Trout JM. Prevalence of Cryptosporidium species and genotypes in mature dairy cattle on farms in eastern United States compared with younger cattle from the same locations. Vet Parasitol 2007;145:260-6.

46. Paul S, Chandra D, Ray DD, Tewari AK, Rao JR, Banerjee PS, et al. Prevalence and molecular characterization of bovine Cryptosporidium isolates in India. Vet Parasitol 2008;153:143-6.

47. Coklin T, Uehlinger FD, Farber JM, Barkema HW, O’Handley RM, Dixon BR. Prevalence and molecular characterization of Cryptosporidium spp. in dairy calves from 11 farms in Prince Edward Island, Canada. Vet Parasitol 2009;160:323-6.

48. Rieux A, Chartier C, Pors I, Paraud C. Dynamics of excretion and molecular characterization of Cryptosporidium isolates in pre-weaned French beef calves. Vet Parasitol 2013;195:169-72.

49. Wegayehu T, Karim R, Anberber M, Adamu H, Erko B, Zhang L, et al. Prevalence and genetic characterization of Cryptosporidium species in dairy calves in Central Ethiopia. PLoS ONE 2016;11:e0154647.

50. Santín M, Trout JM, Fayer R. A longitudinal study of cryptosporidiosis in dairy cattle from birth to 2 years of age. Vet Parasitol 2008;155:15-23.

51. Maikai BV, Umoh JU, Kwaga JKP, Lawal IA, Maikai VA, Cama V, et al. Molecular characterization of Cryptosporidium spp. in native breeds of cattle in Kaduna State, Nigeria. Vet Parasitol 2011;178:241-5.

52. Wang R, Wang H, Sun Y, Zhang L, Jian F, Qi M, et al. Characteristics of Cryptosporidium transmission in preweaned dairy cattle in Henan, China. J Clin Microbiol 2011;49:1077-82.

53. Qi MZ, Fang YQ, Wang XT, Zhang LX, Wang RJ, Du SZ, et al. Molecular characterization of Cryptosporidium spp. in pre-weaned calves in Shaanxi Province, north-western China. J Med Microbiol 2015;64:111-6.

54. Silverlås C, Näslund K, Björkman C, Mattsson JG. Molecular characterisation of Cryptosporidium isolates from Swedish dairy cattle in relation to age, diarrhoea and region. Vet Parasitol 2010;169:289-95.
55. Ng J, Yang R, McCarthy S, Gordon C, Hijjawi N, Ryan U. Molecular characterization of Cryptosporidium and Giardia in pre-weaned calves in Western Australia and New South Wales. Vet Parasitol 2011;176:145-50.

56. Fan Y, Wang T, Koehler AV, Hu M, Gasser RB. Molecular investigation of Cryptosporidium and Giardia in pre- and post-weaned calves in Hubei Province, China. Parasit Vectors 2017;10:519.

57. Castro-Hermida JA, González-Losada YA, Mezo-Menéndez M, Ares-Mazás E. A study of cryptosporidiosis in a cohort of neonatal calves. Vet Parasitol 2002;106:11-7.

58. Trotz-Williams LA, Wayne Martin S, Leslie KE, Duffield T, Nydam DV, Peregrine AS. Calf-level risk factors for neonatal diarrhea and shedding of Cryptosporidium parvum in Ontario dairy calves. Prev Vet Med 2007;82:12-28.

59. Avendaño C, Ramo A, Vergara-Castiblanco C, Sánchez-Acedo C, Quílez J. Genetic uniqueness of Cryptosporidium parvum from dairy calves in Colombia. Parasitol Res 2018;117:1317-23.

60. Trotz-Williams LA, Martin DS, Gatei W, Cama V, Peregrine AS, Martin SW, et al. Genotype and subtype analyses of Cryptosporidium isolates from dairy calves and humans in Ontario. Parasitol Res 2006;99:346-52.

61. Geurden T, Berkvens D, Martens C, Casaert S, Vercruysse J, Claerebout E. Molecular epidemiology with subtype analysis of Cryptosporidium in calves in Belgium. Parasitology 2007;134:1981-7.

62. Benhouda D, Hakem A, Sannella AR, Benhouda A, Cacciò SM. First molecular investigation of Cryptosporidium spp. in young calves in Algeria. Parasite 2017;24:15.

63. Wielinga PR, de Vries A, van der Goot TH, Mank T, Mars $\mathrm{MH}$, Kortbeek LM, et al. Molecular epidemiology of Cryptosporidium in humans and cattle in The Netherlands. Int J Parasitol 2008;38:809-17.

64. Iqbal A, Lim YAL, Surin J, Sim BLH. High diversity of Cryptosporidium subgenotypes identified in Malaysian HIV/AIDS individuals targeting gp60 gene. PLoS ONE 2012;7:e31139.

65. Baroudi D, Hakem A, Adamu H, Amer S, Khelef D, Adjou K, et al. Zoonotic Cryptosporidium species and subtypes in lambs and goat kids in Algeria. Parasit Vectors 2018;11:582.

66. Wagnerová P, Sak B, McEvoy J, Rost M, Sherwood D, Holcomb K, et al. Cryptosporidium parvum and Enterocytozoon bieneusi in American Mustangs and Chincoteague ponies. Exp Parasitol 2016;162:24-7. 